\title{
Engaging Learners via Live Online Learning ${ }^{1}$
}

\author{
Taylor Nash and Megan S. Cantrell ${ }^{2}$
}

\section{Introduction}

The transition to virtual education and training has highlighted opportunities for interactions far beyond what is possible in a face-to-face environment. However, it can be challenging to truly engage and fully hold learners' attention and interaction in online formats. When preparing for virtual training, educators often spend time developing technological skills rather than focusing on the pedagogy, which can lead to mundane, unengaged sessions (Serembus \& Kemery, 2020). Creating learner-centered training using virtual best management practices can prevent nuances from being lost in a virtual setting. This can help learners feel connected and increase their desire to interact in a digital experience (Fosslien \& Duffy, 2020). Extension trainers and educators should use the following engagement strategies for synchronous virtual education.

\section{Strategies for Online Training}

The recommendations in this document can be implemented in both formal and nonformal learning environments. They are divided into three categories based on how each strategy supported participants: increasing involvement, expanding the virtual learning space, and keeping participants' attention on the tasks athand.

Increasing Involvement in Discussions: Facilitators and educators have noted the decrease in learner participation via live online learning systems such as Zoom and Microsoft Teams (Kennedy et al., 2021). Below are best practices to encourage involvement in virtual discussions:
Limit Screen Share during Discussion: When facilitating a discussion, consider not sharing a screen. When having conversation or explaining topics that can be taught effectively through auditory means, limit the time your screen is being broadcast to participants. As a learner, the inability to see all other learners provides a subconscious invitation to not participate. Similar to a participant sitting in the back corner of the classroom, it is beneficial to bring all students to the front row by limiting screen share to pivotal moments.

Use Purposeful Reactions: Reactions are a feature included in most virtual learning platforms. They are buttons participants can select to indicate their reaction toward what is happening. These may look like a thumbs up, clapping hands, or a raise-hand feature. As a virtual educator, creativity is important. While live online learning systems' built-in features are helpful, learners may experience burnout with these features when working in small groups. Consider replacing the consistent use of reactions with other best practices from this list.

Expand Thinking Time: The time between asking a question and expecting an answer is different in a live online course. The virtual format may create a decrease in willing participation (Kennedy et al., 2021). Provide learners with time to think about questions before collecting responses. Consider these strategies:

- Show the questions on a slide and allow participants time to journal about the questions before sharing.

1. This document is AEC734, one of a series of the Department of Agricultural Education and Communication, UF/IFAS Extension. Original publication date August 2021. Visit the EDIS website at https://edis.ifas.ufl.edu for the currently supported version of this publication.

2. Taylor Nash, graduate assistant; and Megan S. Cantrell, lecturer, Department of Agricultural Education and Communication; UF/IFAS Extension, Gainesville, FL 32611.

The Institute of Food and Agricultural Sciences (IFAS) is an Equal Opportunity Institution authorized to provide research, educational information and other services

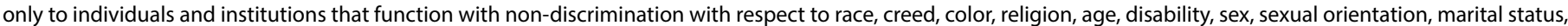

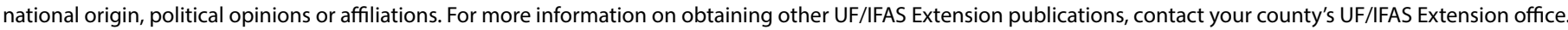
U.S. Department of Agriculture, UF/IFAS Extension Service, University of Florida, IFAS, Florida A \& M University Cooperative Extension Program, and Boards of County Commissioners Cooperating. Nick T. Place, dean for UF/IFAS Extension. 
- Have participants answer the question(s) via virtual means, such as a GoogleDrawing document. GoogleDrawing is a synchronous online platform that lets participants edit and add content in real time virtually. These documents can be created before the lesson and shared with participants during the lesson. While screen sharing should be limited during discussion, intentional inclusion of virtual experiences may require screen sharing to allow participants to engage fully.

Expanding the Virtual Learning Space: The virtual classroom goes beyond using the chat feature and shared screen. Here are some ways to increase participation through expanding the learning space:

Have participants use their cameras to communicate: Encourage learners to use their cameras as part of their learning experience. Ways an educator can engage participants on-camera include the following:

- Have participants hold up a sheet of paper with their answers to a simple question.

- Gauge learner understanding by visual markers.

- Have students use their arm as a vertical marker: Have them hold their arm up to show the extent they agree with a statement. The top of the screen is full confidence, and the bottom of the screen is little confidence.

- Use a range from thumbs up, to thumbs in the middle, to thumbs down.

- Have participants hold up something of the same color to express their choice. For example, red means disagree and green signifies agree.

Move participants away from the camera to complete a task: Virtual learning can happen away from the screen. Consider providing learning opportunities offscreen:

- Share a QR code to access a page that participants can open on their mobile phones, and have students complete an activity before returning to the meeting screen.

- Share a link for learners to watch a video independently and reflect on it.

- Have participants write journal responses to questions while walking around their spaces.

- Working with a small group? Have participants call one another on mobile phones to change scenery.

Change Name, Keep Initials: When trying to keep participants accountable for staying engaged, use their Zoom display name as a place to answer questions.
- Learners can change their names during a meeting if they use the "rename" option.

- Consider having learners keep their initials in their name, so the educator can distinguish between learners who may not share with their camera.

- This is recommended for short responses. If the question is long, consider using a multiple-choice style where students can answer with a single letter.

Keep the Focus: While managing learners' focus is already a challenge for educators in face-to-face settings, doing so virtually can be even more difficult. When trying to keep learners focused, remember to consider what they are doing, thinking, and feeling. This list outlines practices to better keep learners focused on the virtual conversation:

Share the Agenda: When sitting in a live meeting, educators and participants may have difficulty managing time. Sharing an agenda helps participants track their learning and focus their attention. Consider sharing the agenda in the chat to allow learners to access it throughout the meeting.

Music: Distractions are difficult to manage virtually. One way to keep learners engaged is to fill empty space with music (Chalmers et al., 1999). If learners are working independently on a task, slowly joining the meeting room, or on break, consider playing music to limit distractions and minimize burnout from online learning. Engage learners by taking song requests or establishing themes for each class and playing music to match the theme.

Join Breakout Rooms: If using a live online learning system with breakout groups, consider a breakout group as similar to sending a group of learners into the hallway to work independently. Sometimes, the educators should join various breakout rooms and check to see if the groups are working effectively or need any assistance. Online learning can increase learners' anxiety (Kim \& Frik, 2011), which may result in less likelihood for learners to ask for help or clarifications. If the group is too large to meet with each breakout room, consider providing an accountability check by having participants complete a task to bring back to the main session.

PowerPoints: When using PowerPoint, it is important to keep the screen interactive. Interactive could mean limiting the amount of information per slide so the educator flips through slides more quickly, without pressuring the learners' ability to read long blocks of text. If a lot of information needs to be shared on the screen, consider annotating important information as you teach. Annotations can look like bolding important words, underlining statements, or 
changing the color of important parts of the slide. Have annotations change as the information is covered.

Intentional Screen Breaks: Giving breaks is important. Learners need time to walk away from the screen. However, many learners are likely to use their break scrolling through social media or responding to notifications on their mobile device, which results in continued screen time. When assigning breaks during a training or workshop, encourage learners to step away from the screen by providing other options for activities to do. Some examples of directions for an intentional break include:

- "Walk around your house/apartment/room and find something that relates to this concept."

- "During this break, I will play a song. Feel free to get up and move around, just be back by the end of the song."

- "Take five minutes to grab a snack or a drink if you need." Ask learners to share their snacks upon their return.

\section{Summary}

Online learning is a way to connect and educate learners across distance in a timely and fiscally friendly manner. However, the increased popularity of live online learning has led to new challenges of engaging and motivating learners in a virtual environment. This document includes strategies and recommendations to mitigate the challenge of keeping learners' attention and increasing participation during synchronous online classes and meetings.

\section{References}

Chalmers, L., Olson, M. R., \& Zurkowski, J. K. (1999).

Music as a classroom tool. Intervention in School and Clinic, 35(1), 43-52. https://doi.org/10.1177/105345129903500108

Fosslien, L., \& Duffy, M. W. (2020). How to combat zoom fatigue. Harvard Business Review. https://hbr.org/2020/04/ how-to-combat-zoom-fatigue

Kennedy, J., Holcombe-James, I., \& Mannell, K. (2021). Access denied: How barriers to participate on Zoom impact on research opportunity. M/C Journal, 24(3).

Kim, K. J., \& Frick, T. W. (2011). Changes in student motivation during online learning. Journal of Educational Computing Research, 44(1), 1-23. https://doi.org/10.2190/ EC.44.1.a
Serembus, J. F., \& Kemery, D. C. (2020). Creating dynamic learning with zoom. Nurse Educator, 45(6), 291-293. https://doi.org/10.1097/NNE.0000000000000915 